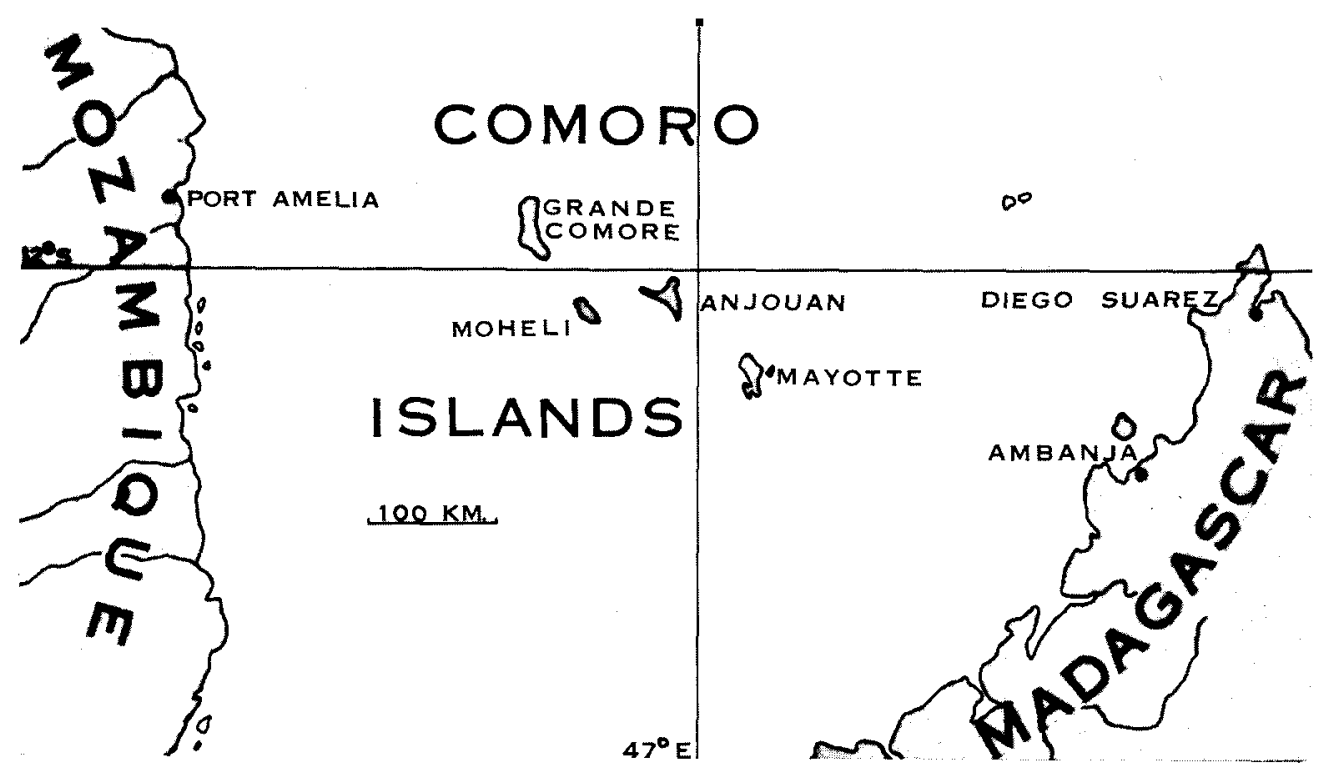

\title{
The Lemurs of the Comoro Islands
}

\section{lan Tattersall}

The Comoro lemurs, the only wild lemur populations outside Madagascar, are protected and seem secure. But after spending seven months in the islands the author believes that they could become threatened if forest destruction, particularly of the protected forest, continues at the present rate. He urges the need to enforce both forest protection and the hunting laws.

The Madagascar lemurs have received considerable attention, but few people realise that there are lemurs also on the Comoro Islands, although they are the only other wild lemurs in the world. With pressures on the Madagascar lemurs intensifying - thanks to a burgeoning human population, habitat destruction, hunting, and the breakdown of traditional taboos on killing certain species - the Comoro lemurs should be of considerable concern. These notes are the result of fieldwork November 1974 to June 1975.

Two wild lemur populations are established in the islands, both of the genus Lemur: L. mongoz (L. m. mongoz of most recent authors) and L. fulvus. The former, which is also found in north-west Madagascar, occurs on Mohéli (290 sq km) and Anjouan (424 sq km). The subspecies L.f. mayottensis is unique to Mayotte ( $375 \mathrm{sq} \mathrm{km})$; in appearance it is very like $L$. f. fulvus, also found in north-west Madagascar, from which it is probably derived. These three islands are all more or less well watered, but Grande Comore, the largest island, has virtually no permanent water, and the few lemurs in its forests (all of Comorian subspecies) are captive animals that have escaped or been set free. It is impossible to be certain when or how lemurs were introduced to the Comoros from Madagascar; they could well have arrived by rafting on the floodwaters of the Betsiboka River; equally, of course, and perhaps much more plausibly, they could have been introduced by man, 
of a watercourse. Enforcement of these would probably ensure an adequate habitat for the lemurs, and would certainly do so if the limit were doubled to 30 metres. But in many areas forest has been destroyed right up to the water's edge, with the result that many streams which formerly ran throughout the year are now only seasonal. Obviously both economic and conservation interests would be equally well served by the protection of the forests, especially in the Anjouan highlands where the humid forests attract and conserve precipitation, and control its drainage, thereby protecting the lower slopes from large-scale erosion while providing their cultivators with an adequate year-round supply of ground water. But they are rapidly disappearing. Prohibition of forest clearing in the central massif above, say, 800 metres, is clearly essential, and the same recommendations apply to other high areas, for example above the 500-metre contour in Mohéli and the elevated regions of Benara and Majimbini in Mayotte.

\section{Acknowledgments}

The survey on which this short report is based could not have been carried out without the generous co-operation of the Comorian authorities and others. Among those whom I would especially like to thank are Mm. Omar Tamou, Mouhtar Rachide, Francis Debuissy and Robert Tapia of Moroni, Grande Comore, Mm. Swabahaddine Ben Said Mohamed and Ibrahim Mohamed of Mutsamudu, Anjouan, and Mm. Ahmed Abdallah, of Mamutzu, Mayotte. IRAT Comores, and its Director, M. Jacques Larcher, and Mayotte representative, M. Henri Reneaud, provided invaluable help, as did $\mathrm{M}$. and Mme J-C Favetto of Moroni and $M$. and Mme Christian Gaiani of Pamanzi, Mayotte. Finally, my thanks to my wife, Christine, and to the National Geographic Society of Washington DC whose financial support made the field work possible.

\section{Note}

Since this report was originally prepared, considerable political changes have taken place in the Comoros. The islands of Grande Comore, Anjouan and Mohéli now constitute an independent republic, while Mayotte remains French and will become an Overseas Department of France. Representations about the protection of the lemurs are currently being made to both sets of authorities.

Ian Tattersall, American Museum of Natural History, Central Park West at 79th Street, New York, New York 10024, USA.

\section{Climate and Conservation}

Until recently climatology has been one of the most neglected aspects of the data needed for adequate conservation research, but fortunately the deficiency is becoming generally recognised. Climates of the States, in two volumes, by Officials of the National Oceanic and Atmospheric Administration, is described as 'a practical reference containing basic climatological data of the United States'. It is published by the Water Information Center, Port Washington, NY 11050, \$45. Reference works such as these should be on the shelves of all important conservation libraries. The two volumes (split east/west) give a full range of rainfall and temperature statistics, together with much background material, including not only Alaska and Hawaii but also Puerto Rico and the Virgin Islands. Only the District of Columbia appears to be missing. The desirability of compiling similar volumes for Europe and Africa may be commended to the Council for Europe and the OAU. 